\title{
Gene Routes in Colorectal Cancer
}

\author{
Asif Meraj, Mudassir khan and Rauf Wani* \\ General \& Minimal Invasive Surgery, Sher-i-Kashmir Institute of Medical sciences, India
}

Submission: March 05, 2018; Published: March 12, 2018

"Correspondence Address: Rauf Wani, Colorectal division, General \& minimal Invasive Surgery, Sher-i-Kashmir Institute of Medical Sciences, Srinagar, Kashmir, India, Email: raufw64@hotmail.com

\section{Mini Review}

Colorectal cancer results from an accumulation of genetic abnormalities in the nuclei of colonic cells that allow the cells to escape the normal controls on cellular growth, death, and differentiation. The causes of these genetic abnormalities include mutations that happen during various phases of cell division, elements of life-style, personal characteristics, and inheritance. Each colorectal cancer is genetically unique, with hundreds of different mutated genes. However, the number of genes which when mutated drive carcinogenesis forward is limited [1]. Despite the genetic heterogeneity displayed in colorectal cancers there are three main routes (Figure 1) through which colorectal cancer develops [2]. These three routes produce cancers of different biology. It is important to distinguish between the routes, because the differences in biology have different clinical implications.

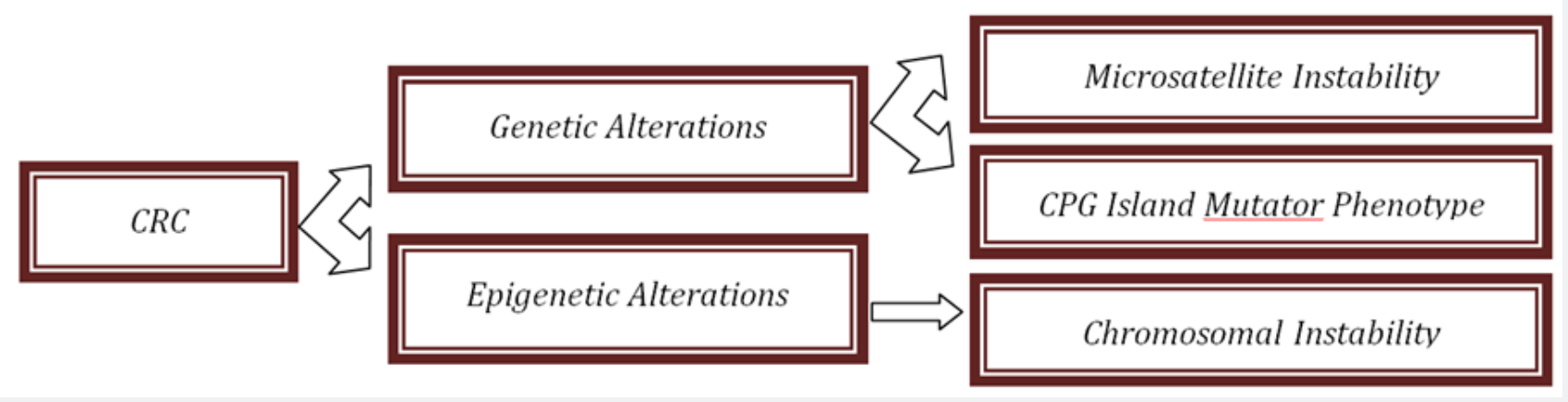

Figure 1: Genetic pathways in colorectal cancer.

Before going on to discuss the genetic pathways in colorectal cancer, let us define few basic genetic terminology. A gene is a sequence of nucleotide bases in DNA that codes for a specific protein. The genetic code is based on triplets of nucleotide bases, called codons, which encode a specific amino acid. A protein is a sequence of amino acids that performs a specific function in a cell. The nucleotide code is redundant as there are many more codons than amino acids. Thus, the actual DNA sequence can vary considerably yet still produce a consistent functioning protein. However, when changes in the DNA sequence result in a gene that encodes an abnormally functioning protein, a genetic disease may arise. This is an underlying process in cancer.

Hence, cancer is uncontrolled cell growth that results from an alteration in the normal checks and balances of cellular homeostasis. In normal cellular processes, there is a balance between the proteins produced by proto Oncogene and tumor suppressor genes. Inappropriate activation of proto-Oncogene or inactivation of tumor suppressor genes produces uncontrolled acceleration of cell growth that can ultimately lead to neoplasia. The most common way these genes are inactivated or activated is by mutation. A mutation is a permanent structural change in the DNA sequence. Some mutations are harmless due to the redundancy of the code, however, a deleterious mutation is one associated with a harmful change in the structure of the protein, which causes abnormal function. While a mutation is the most common way in which gene function is lost or disordered, other processes contribute to cancer development.

Genetic mechanisms involve the primary DNA sequence and changes or mutations to this sequence, whereas Epigenetics is the study of heritable changes in gene expression (active versus 


\section{Cancer Therapy \& Oncology International Journal}

inactive genes) that do not involve changes to the underlying DNA sequence - a change in phenotype without a change in genotype - which in turn affects how cells read the genes (Figure 2).

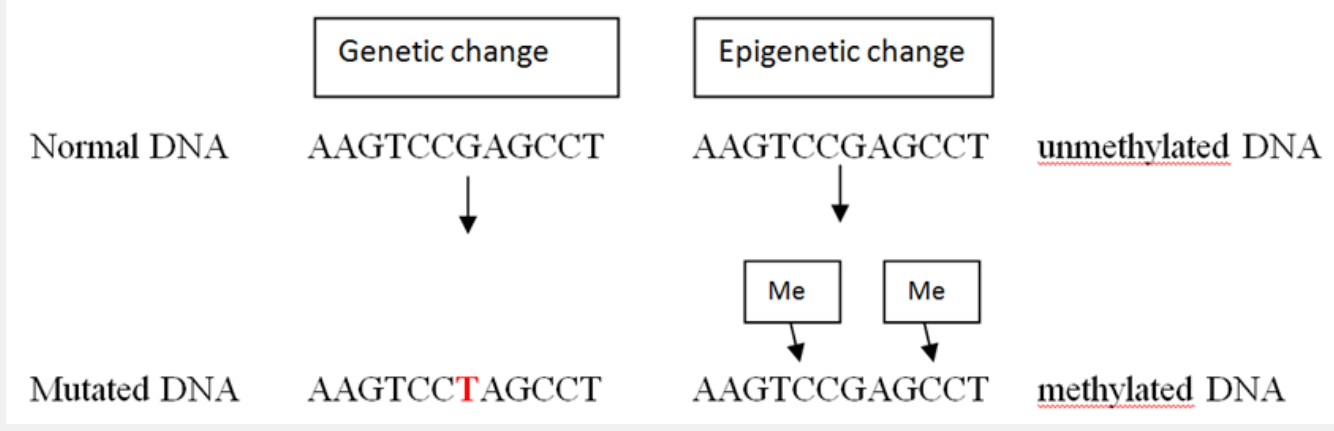

Figure 2: Difference between genetics and epigenetics

\section{Microsatellite Instability}

Microsatellites are short repeating nucleotide base sequences that are prone to slippage during DNA replication that creates loop mismatches. Unrepaired mismatches are apparent as "unstable" microsatellites, where the length of a particular microsatellite in a tumor is different compared to that in a normal cell. The Micro Satellite Instability (MIS) pathway represents a form of genomic instability involved in the genesis of approximately $15 \%$ of sporadic colorectal cancer and $>95 \%$ of Hereditary Non Polyposis Colorectal Cancer (HNPCC) syndrome. MSI is caused by the inactivity of the DNA Mismatch Repair (MMR) system. Disabled DNA MMR causes a 100-fold increase in the mutation rate in colorectal mucosa cells [3]. The MMR system is a multi-protein system, which acts like a proofing machine to increase the fidelity of DNA replications by identifications and direct repair of mismatched nucleotides [4,5]. The MMR system acts only when an error eludes the intrinsic error checking system of DNA polymerase [4].

CRC that develops through the MSI pathway presents peculiar clinical features: more often located in the proximal colon, with a poorly differentiated and a mucinous or medullary histotype, and often presents intense peritumoral and intratumoral lymphocytic infiltrations [6]. In general, the prognosis and survival of patients affected by MSI-high CRC is better and longer than that of patients with Chromosomal instability (CIN) positive CRC [6]. Multiple lines of evidence support that MSI-High tumors have worse prognosis when treated with 5-fluorouracil-based chemo-therapy alone [7]. However, such tumors do seem to respond to oxaliplatin and irinotecan [8]. Most recently, MSI-H tumors have been shown to respond very well to the use of PD-1 blocking agents [9]. This is thought to be the effect of amplifying the T-cell response to the immunogenic products of the mutator phenotype.

\section{Chromosomal Instability}

Chromosomal instability (CIN) is represented by the classic "Vogelgram," [10] (Figure 3) beginning with an inactivating mutation in the gateway driver gene APC and progressing through other driver mutations in KRAS, SMAD4, and TP53. The APC mutation predisposes the cell to chromosomal instability, which leads to Loss of heterozygosity and aneuploidy. CIN is the most common and well characterized type of colorectal pathway. The tumorigenic process involves different mitotic spindle checkpoint regulators and proteins that mutually influence mitotic chromosome stability $[11,12]$.

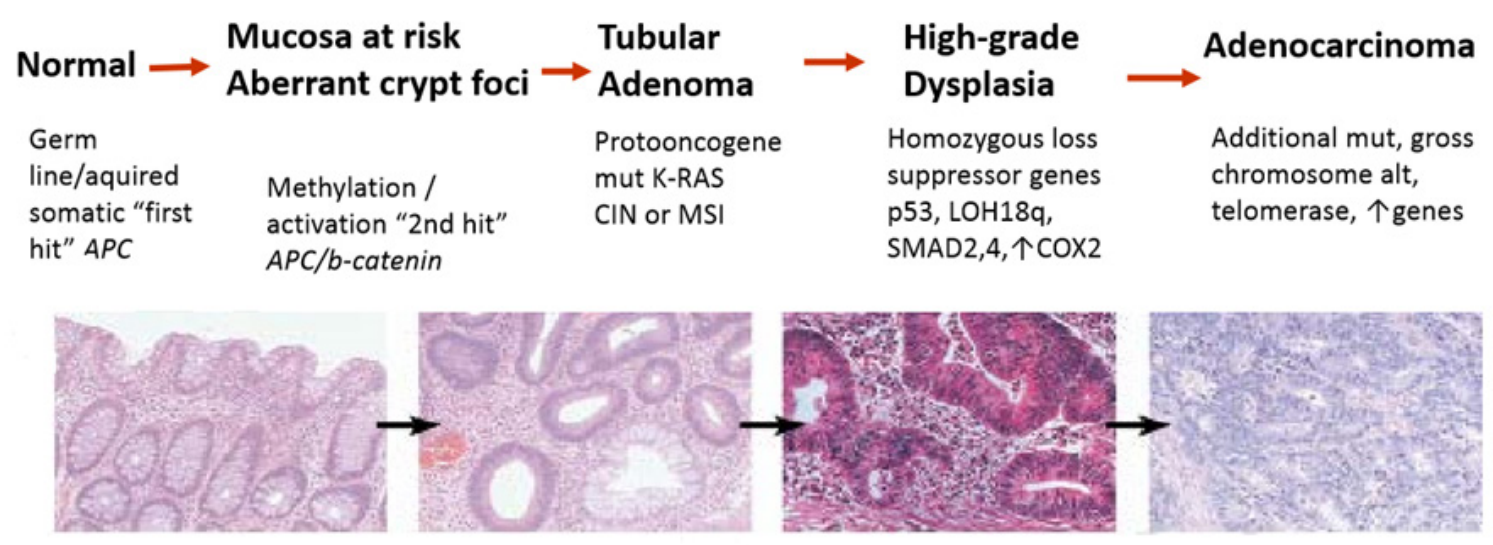

Figure 3: Adenoma carcinoma sequence. 


\section{Cancer Therapy \& Oncology International Journal}

A "key" initial mutation is the early mutation of the adenomatous polyposis coli (APC) tumor suppressor gene, involved in both sporadic CIN and, when germline mutated, in all Familial Adenomatous Polyposis (FAP) $[13,14]$. This is followed by subsequent events that promote new mutations and facilitate the tumour's progression from benign to malignant stages. The adenoma to carcinoma transition is determined firstly by the $\mathrm{K}$-ras gene. p53 loss of function is frequently present in the later stages of colorectal tumorigenesis [15]. The p53 gene is located on chromosome $17 \mathrm{p}$ and its mutation is one of the key steps in colorectal carcinogenesis and stimulates high proliferative activity through the loss of cell cycle control and apoptosis. An often co-occurring molecular alteration with the p53 loss is the LOH of chromosome 18q [16], where the genes Smad2, Smad4 and DCC genes are located. $\mathrm{LOH}$ of $18 \mathrm{q}$ has been associated with a strong negative prognosis in colon cancer, in particular with high metastatic potential [17]. Other alterations associated with CIN pathway include phosphoinositide-3 kinase (PI3KCA) signaling pathway [18], LINE-1 (long interspersed nucleotide element-1) [19], kinetochore (Centromere protein (CENP)-A and CENP-H) [20], Hypoxia Inducible Factor (HIF)-1 and HIF-2 [21] and cathepsin B (CTSB) [22].

\section{CIMP Pathway}

CIMP pathway consists of the aberrant hypermethylation of $\mathrm{CpG}$ dinucleotide sequences localized in the promoter regions of genes involved in cell cycle regulation, apoptosis, angiogenesis, DNA repair, invasion and adhesion. The initial event is a gene mutation in either BRAF or KRAS. Methylation of various other driver genes then advances to neoplasia that is apparent histologically as serrated mucosal lesions such as hyperplastic polyps, sessile serrated adenomas/polyps, and dysplastic serrated polyps [23]. These cancers are CIMP-positive. The promoter hypermethylations cause the loss of gene expression. CIMP is found in approximately $20 \%-30 \%$ of CRC and it was reported that clinical features of CIMP CRCs are similar to those associated with MSI [24]. Based on the number of methylated markers, the CIMP phenotype can be also divided into CIMP-high and CIMP-low. The BRAF oncogene mutation is often identified in CIMP-high CRC and is associated with increased cell growth, progression of carcinogenesis, and high colon cancer specific mortality [25]. However CIMP-high tumors, regardless of BRAF mutation, are associated with reduced colon cancer mortality [25]. BRAF and KRAS mutations are mutually exclusive [26]. KRAS mutation is usually found in CIMP low CRCs. This is also frequently associated with mutations in the DNA repair gene

\section{Conclusion}

The knowledge of different molecular pathway involvement in colorectal cancer development has helped us to understand how colorectal cancer initiates and progresses. The specific treatment options can target particular gene to prevent further progression of the disease. Prognostication and response to various adjuvant therapies is based on understanding of genetic pathways in colorectal cancer.

\section{References}

1. Wood LD, Parsons DW, Jones S, Lin J, Sjöblom T, et al. (2007) The genomic landscapes of human breast and colorectal cancers. Science 318: 1108-1113.

2. Vogelstein B, Kinzler KW (2015) The path to cancer -three strikes and you're out. N Engl J Med 12: 1895-1898.

3. Thomas DC, Umar A, Kunkel TA (1996) Microsatellite instability and mismatch repair defects in cancer. Mutat Res 350(1): 201-205.

4. Fishel R (1998) Mismatch repair, molecular switches, and signal transduction. Genes Dev 12(14): 2096-2101.

5. Boland CR, Thibodeau SN, Hamilton SR, Sidransky D, Eshleman JR, et al. (1998) A National Cancer Institute Workshop on Microsatellite Instability for cancer detection and familial predisposition: Development of international criteria for the determination of microsatellite instability in colorectal cancer. Cancer Res 58(22): 5248-5257.

6. Lanza G, Gafà R, Maestri I, Santini A, Matteuzzi M, et al. (2002) Immunohistochemical pattern of MLH1/MSH2 expression is related to clinical and pathological features in colorectal adenocarcinomas with microsatellite instability. Mod Pathol 15(7): 741-749.

7. Webber EM, Kauffman TL, O Connor E, Goddard KA, et al. (2015) Systematic review of the predictive effect of MSI status in colorectal cancer patients undergoing 5FU-based chemotherapy. BMC Cancer 15: 156.

8. Kim JH, Bae JM, Oh HJ, Lee HS, Kang GH, et al. (2015) Pathologic factors associated with prognosis after adjuvant chemotherapy in stage II/III microsatellite-unstable colorectal cancers. J Pathol Transl Med 49(2): 118-128.

9. Le DT, Uram JN, Wang H (2015) PD-1 blockade in tumors with mismatch-repair deficiency. N Engl J Med 372: 2509-2520.

10. Vogelstein B, Fearon ER, Hamilton SR, Kern SE, Preisinger AC, et al (1988) Genetic alterations during colorectal-tumor development. N Engl J Med 319(9): 525-532.

11. Bardi G, Johansson B, Pandis N, Mandahl N, Bak-Jensen E, et al (1993) Cytogenetic analysis of 52 colorectal carcinomas-Non-random aberration pattern and correlation with pathologic parameters. Int J Cancer 55(3): 422-428.

12. Bardi G, Sukhikh T, Pandis N, Fenger C, Kronborg O, et al. (1995) Karyotypic characterization of colorectal adenocarcinomas. Genes Chromosomes Cancer 12(2): 97-109.

13. Shih IM, Zhou W, Goodman SN, Lengauer C, Kinzler KW, et al. (2001) Evidence that genetic instability occurs at an early stage of colorectal tumorigenesis. Cancer Res 61(3): 818-822.

14. Sieber OM, Lamlum H, Crabtree MD, Rowan AJ, Barclay E, et al. (2002) Whole-gene APC deletions cause classical familial adenomatous polyposis, but not attenuated polyposis or "multiple" colorectal adenomas. Proc Natl Acad Sci USA 99(5): 2954-2958.

15. Baker SJ, Preisinger AC, Jessup JM, Paraskeva C, Markowitz S, et al. (1990) p53 gene mutations occur in combination with $17 \mathrm{p}$ allelic 


\section{Cancer Therapy \& Oncology International Journal}

deletions as late events in colorectal tumorigenesis. Cancer Res 50(23): 7717-7722.

16. Lanza G, Matteuzzi M, Gafá R, Orvieto E, Maestri I, et al. (1998) Chromosome 18q allelic loss and prognosis in stage II and III colon cancer. Int J Cancer 79(4): 390-395.

17. Kern SE, Fearon ER, Tersmette KW, Enterline JP, Leppert M, et al. (1989) Clinical and pathological associations with allelic loss in colorectal carcinoma. JAMA 261(21): 3099-3103.

18. Deming DA, Leystra AA, Nettekoven L, Sievers C, Miller D, et al. (2013) PIK3CA and APC mutations are synergistic in the development of intestinal cancers. Oncogene 33(17): 2245-2254.

19. Cordaux R, Batzer MA (2009) The impact of retrotransposons on human genome evolution. Nat Rev Genet 10(10): 691-703.

20. Tomonaga T, Matsushita K, Ishibashi M, Nezu M, Shimada H, et al. (2005) Centromere protein $\mathrm{H}$ is up-regulated in primary human colorectal cancer and its over expression induces aneuploidy. Cancer Res. 65(11): 4683-4689.

21. Baba Y, Nosho K, Shima K, Irahara N, Chan AT, et al. (2010) HIF1A overexpression is associated with poor prognosis in a cohort of 731 colorectal cancers. Am J Pathol 176(5): 2292-2301.
22. Chan AT, Baba Y, Shima K, Nosho K, Chung DC, et al. (2010) Cathepsin $\mathrm{B}$ expression and survival in colon cancer: Implications for molecular detection of neoplasia. Cancer Epidemiol. Biomark Prev 19(11): 2777 . 2785.

23. Sakai E, Fukuyo M, Ohata K, Matsusaka K, Doi N, et al. (2016) Genetic and epigenetic aberrations occurring in colorectal tumors associated with serrated pathway. Int J Cancer 138(7): 1634-1644.

24. Ogino S, Odze RD, Kawasaki T, Brahmandam M, Kirkner GJ, et al. (2006) Correlation of pathologic features with CpG island methylator phenotype (CIMP) by quantitative DNA methylation analysis in colorectal carcinoma. Am J Surg Pathol 30(9): 1175-1183.

25. Ogino S, Nosho K, Kirkner GJ, Kawasaki T, Meyerhardt JA, et al. (2009) CpG island methylator phenotype, microsatellite instability, BRAF mutation and clinical outcome in colon cancer. Gut 58(1): 90-96.

26. Chan TL, Zhao W, Leung SY, Yuen ST (2003) BRAF and KRAS mutations in colorectal hyperplastic polyps and serrated adenomas. Cancer Res 63(16): 4878-4881. 